\title{
A REVIEW OF THREE DECADES OF RESEARCH ON SOME COMBINATORIAL OPTIMIZATION PROBLEMS
}

\author{
Horacio Hideki Yanasse
}

Received October 8, 2012 / Accepted March 15, 2013

\begin{abstract}
This paper presents an overview of our research in combinatorial optimization problems. Over the last three decades, our team has been studying mostly optimization problems that arise in industrial environments through the elaboration and solution of mathematical decision models. In addition to elaborating innovative models, we have improved upon existing solutions to complex problems, helping decision makers and researchers to better understand complex industrial systems. Our work has focused on the development of computationally more efficient algorithms that improve on existing methods by improving the solution quality or reducing the computation effort to obtain good solutions. While some of our earlier work became less necessary with the speed up of the computational facilities, the search for improved solution quality and reduced computational effort continues. After reviewing our findings on lot sizing, production scheduling, cutting problems, pattern sequencing, tool switches in flexible manufacturing machines and integrated cutting and sequencing problems, we propose topics for future study.
\end{abstract}

Keywords: review, works by HHYanasse, combinatorial optimization.

\section{INTRODUCTION}

During the past 30 years we have studied various complex problems common to industrial settings. We have tried to elaborate and solve mathematical decision models that may help decision makers to understand these systems better.

Most of the models studied are in the combinatorial optimization area. Our research has been in the development of improved computational algorithms to solve these decision models or to find ways to solve the modeled problems directly. Our goal has been to develop better solution methods than those proposed in the literature in terms of the quality of the solutions obtained, or the reduction of the computational effort required to obtain good solutions by identifying particular properties of the problems studied, the existence of special structures in the mathematical models that represent the problems, or particular properties of optimal solutions for the problem

Instituto Nacional de Pesquisas Espaciais - INPE, Avenida dos Astronautas, 1.758, São José dos Campos, SP, Brasil. E-mail: horacio@lac.inpe.br

Current address: UNIFESP - Campus São José dos Campos-SP. Rua Talim, n. 330, São José dos Campos, SP, Brasil.

E-mail: horacio.yanasse@unifesp.br 
which could be exploited in an algorithm. Our intention has always been to find optimal solutions to the problems through the use of exact methods, but we have also developed heuristics to obtain good upper bounds. For exact methods, good lower bounds are also essential for fast convergence. Therefore, we also attempted to determine stronger lower bounds for the optimal solution value of some of the problems as compared to the ones of the literature.

There is still theoretical interest in the optimization problems we have addressed because they are computationally difficult to solve, making them a real challenge to researchers. There is also practical interest in the research conducted since it may lead to a better use of limited resources, minimizing costs and/or maximizing returns.

In this paper we review some of our collective results for decision problems regarding: lot size, production scheduling, one-dimensional knapsack, subset sum, cutting, sequencing patterns, tool switches in flexible machines, and integrated cutting and sequencing problems.

\section{REVIEW OF RESULTS}

\subsection{Lot size problems}

In lot size problems, we are interested in determining how much to produce of each product in order to meet varying demands at minimal cost for production and storage. Discrete periods in time, dynamic demands, and a finite horizon are assumed. The production is in lots and we incur a fixed cost each time a batch is produced. The basic formulation of the lot size problem studied is

$$
v(P)=\min \sum_{i=1}^{N} \sum_{t=1}^{T}\left(s_{i t} \delta\left(x_{i t}\right)+h_{i t} I_{i t}+v_{i t} x_{i t}\right)
$$

subject to

$$
\begin{array}{lrl}
x_{i t}-I_{i t}+I_{i, t-1}=d_{i t} & i=1, \ldots, N ; & t=1, \ldots, T \\
x_{i t}>0 ; I_{i t} \geq 0 & i=1, \ldots, N ; & t=1, \ldots, T \\
\sum_{i=1}^{N}\left(r_{i} \delta\left(x_{i t}\right)+m_{i} x_{i t}\right) \leq C_{t} & t=1, \ldots, T \\
I_{i 0}=0, I_{i T}=0 & i=1, \ldots, N \\
\delta\left(x_{i t}\right)=1 \quad \text { if } x_{i t}>0 & \\
0 \quad \text { otherwise } & i=1, \ldots, N ; \quad t=1, \ldots, T
\end{array}
$$

where

$x_{i t}$ is the quantity of product $i$ produced in period $t$;

$I_{i t} \quad$ is the inventory carried from period $t$ to period $t+1$ of product $i$;

$s_{i t} \quad$ is the fixed cost to produce product $i$ in period $t$;

$h_{i t}$ is the unit inventory cost of product $i$ in period $t$; 


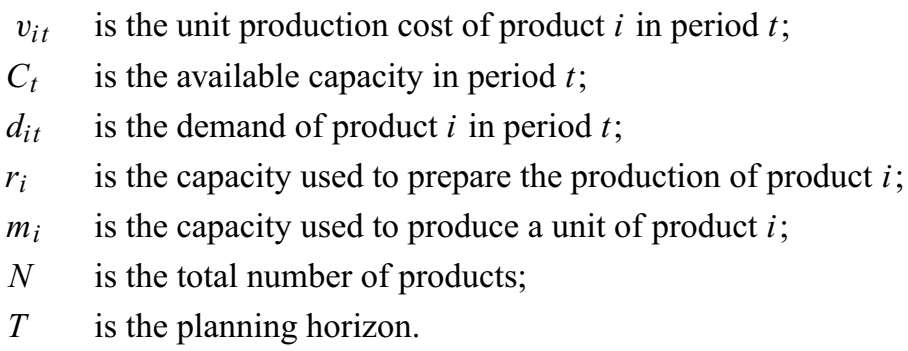

We initially analysed the non-capacitated case, that is, the problem without constraints (4). The problem then decomposes into $N$ non-capacitated lot size problems.

Next, we analyzed some heuristic methods to solve them. We presented worst-case error bounds for these heuristics, providing theoretical support for their application. The first worst-case relative error calculated was of the Silver and Meal heuristic (Peterson \& Silver, 1979). We showed that its relative error can be arbitrarily large in the worst case. We proposed two other related heuristics with maximum error, in the worst case, of 2 . The basic idea of these heuristics was to produce the product whenever the storage cost exceeded the preparation cost. From a practical point of view, the Silver and Meal's heuristic was used with success because it presented a small average error. But the result that we obtained should alert the user that, in some special pathological cases, the error can be very large.

Another approximation considered was the reduction of the planning horizon. Such reduction can be considered when long term forecasting and handling data is difficult. After dividing the original problem into two smaller problems, we show that the error in the worst case, does not exceed a fixed cost for the single product case.

Another approximation considered was the aggregation of products. Two or more products that present a factor of proportionality in their parameters follow identical production strategies. This fact served as the basis for the proposed aggregation scheme. In practice, however there is rarely such a proportionality of the parameters. Hence, we derived errors, in the worst case, which were a function of the differences in proportionality.

All these results for the non-capacitated problem were relevant at the time the research was conducted in the late 70's and early 80's in view of the low computing power available at the time. Currently, with the existing computational power, these results are less relevant to industry but not to science.

Studies were also carried out to discover the computational complexity of the capacitated lot size problem. Several cost structures were considered for the problem that may arise in practical cases. We analyzed the cases of a single product and we identified classes of problems that could be solved by polynomial algorithms. Algorithms were developed for these polynomial classes and classes that are NP-hard. Next, we proved that, for multiple products the problem is NPcomplete, even for similar classes in which the problem is polynomial time solvable for the case of a single product. 
We also studied a deterministic approximation to a stochastic lot size problem. Given the difficulties in solving a stochastic sequential decision process problem, we proposed solving a related non-sequential stochastic problem in its place. To capture the sequential nature of the actual decision-making process, we proposed that the non-sequenctial problem be solved using a rolling horizon, thereby incorporating new information as it became available. Bounds for this proposed approximation were derived, indicating that the approximation was good.

We also applied an aggregate production planning model to an aeronautical industry and an inventory planning problem of items for repair, in a maintenance program of a transportation fleet.

We later studied a particular case where a price increase might require an exception lot on an EOQ standard model (i.e., continuous time). To determine this lot, we proposed the use a minimization of the maximum error criterion of the cumulative costs, avoiding the problem of comparing policies with stocks that are not in phase, as used in previous studies.

Details of the results that we reviewed in this section can be obtained in Yanasse $(1981,1987$, 1990), Bitran \& Yanasse (1982, 1984), Bitran, Magnanti \& Yanasse (1982a,b, 1984a,b), Contador \& Yanasse (1983), Contador, Gartenkraut \& Yanasse (1984), Hirata \& Yanasse (1983), Lima \& Yanasse $(1985,1986)$.

\subsection{Cutting problems}

\subsubsection{One-dimensional knapsack problem}

In the one-dimensional cutting problem we have a bar (object) of a certain length from which we want to cut smaller items, according to some objetive function. In this context, a basic problem to be solved is the well-known one-dimensional knapsack problem.

The basic model for the one-dimensional knapsack problem is:

$$
\begin{array}{ll} 
& v(P)=\max z=\sum_{j=1}^{n} c_{j} x_{j} \\
\text { subject to } & \sum_{j=1}^{n} a_{j} x_{j} \leq b \\
& x_{j} \in \mathbb{N} \quad j=1, \ldots, n,
\end{array}
$$

where we assume that $b, c_{j}$ and $a_{j}$, are all non-negative integers, where $j=1, \ldots, n$ and $\mathbb{N}$ is the set of the natural numbers.

We considered the particular case where in constraint (8) we have equality rather than inequality. With the equality constraint, many algorithms for the knapsack problem suggested in the literature cannot be applied. We developed a pseudo-polinomial enumerative algorithm for the knapsack problem for the case of equality based on the determination of the number of solutions of linear Diophantine equations. This algorithm reduced computational effort and memory requirements compared to other exact methods described in the literature that use dynamic programming. 
Another specific case considered was when the variables $x_{j}, j=1, \ldots, n$, are limited to the values 0 or 1 and the ratio $\left(c_{j} / a_{j}\right), j=1, \ldots, n$, is a constant. In this case, the knapsack problem is called the $0-1$ value independent knapsack problem. This problem is considered more difficult to solve due to the constant ratio $\left(c_{j} / a_{j}\right), j=1, \ldots, n$, which hinders the performance of the vast majority of existing algorithms by the difficulty of obtaining good bounds for the problem.

In practice, this problem appears, for example, as a subproblem of a more general problem, which is the two-dimensional guillotine cutting stock problem. We also developed a pseudopolinomial algorithm for this case which is an adaptation of an earlier algorithm we developed for the 0-1 linear Diophantine equation. This adaptation maintained the same complexity of previous algorithms, but it has a larger computational memory requirement.

An enumerative scheme similar to the previous ones was also developed to determine the $K$-best $(K \geq 1)$ solutions of the problem (7)-(9). The computational complexity of the proposed scheme is limited by $\mathrm{O}(K n b)$ and the memory requirements are limited by $\mathrm{O}(n b)$. The enumerative scheme proposed, in fact, can be seen as a different (and improved) implementation of a dynamic programming algorithm for solving the knapsack problem.

We also participated in the development of parallel algorithms for the subset sum problem which is a particular case of the $0-1$ value independent knapsack problem. We developed a parallel algorithm that, to the best of our knowledge, was the only one which was simultaneously scalable with optimal cost for solving the subset sum problem in a CREW PRAM, based on Horowitz and Sahni's two-list approach (Horowitz \& Sahni, 1974). We also developed new parallel scalable algorithms in the PRAM model for the subset sum problem, based on specific dynamic programming algorithms that differed from Bellman's approach (Bellman, 1957). The time and space bounds of these new algorithms were better than the direct parallelization of Bellman's algorithm, which was the most efficient known result at the time.

In addition we studied a special cutting problem where the knapsack had compartments. We modelled this problem as a linear integer programming problem. Earlier studies formulated it as a non-linear problem.

Details of the results that we reviewed in this section can be obtained in Yanasse \& Soma (1985a,b, 1987a,b, 1990, 1993), Soma, Zinober, Yanasse \& Harley (1995), Yanasse, Soma \& Maculan (1994, 2000), Soma \& Yanasse (1985, 1986, 1987a,b), Maculan, Soma \& Yanasse (1996), Sanches, Soma \& Yanasse (2001, 2002, 2007, 2008, 2010), Yanasse, Hoto, Spolador \& Arenales (2005).

\subsubsection{Two-dimensional assortment problems}

The two-dimensional cutting stock problem we considered is the cutting of rectangular wooden plates (objects) into smaller rectangular panels (items) of various sizes. The saw imposes certain conditions on how the plates must be cut and, the main one is that the cut must be guillotine and orthogonal, i.e. the saw cuts straight across the plate, parallel to one of its sides. 
We discussed some cases of selection of plate sizes (assortment problems) for cutting the panels required according to different criteria, usually, minimizing material loss.

The first problem studied was the case where there are different sizes of plates available from which the items can be cut. The problem consists in determining the best mix of plates and the corresponding cutting patterns in order to satisfy the demand exactly, with minimal loss. Two dimensional assortment problems had been little discussed in the literature at that time. With respect to the cutting patterns, in addition to being guillotined, the following restrictions were imposed: trimmings (the sides of the plates usually require a finish); the saw width (material is lost when a cut is made), head cuts (the machine has two saws and the plate is initially cut into two parts - the head and the main section - each of which is then cut according to restrictions imposed by the machine); complexity of the cutting patterns (for example, extra cuts were allowed up to a certain stage), and rotation constraints of the material.

Given the computational limitations at the time, a heuristic to generate good cutting patterns for the problem was developed and, to determine the mix of plate sizes to cut the panels with minimum loss, an enumerative mechanism combining plates in descending order of area was proposed. Each combination of this list was tested and the first feasible one was selected as the solution to the problem. The cutting stock problem was solved using a sequential procedure; i.e. given a plate, the best possible pattern is generated and this pattern is included in the solution. This pattern is used as much as possible, meeting the demand of the items without overproducing any of them. The residual demand is updated (demand not met) and the same procedure is applied again with the next plate. This is repeated until all demand is satisfied. This was one of the first studies published in the literature that considered different sizes of plates in a two-dimensional cutting stock problem with patterns with practical constraints.

A second problem considered the situation in which you may order plates with the "ideal" length from which the required items are to be cut. Given a range of the possible plate lengths that can be delivered, what should be the size to order, taking into consideration the required items to be cut? To the best of our knowledge, this problem had not been considered before in the literature. To present a good solution to this problem, we developed a procedure that made a controlled search of the lengths for the plate within the range set by the supplier. Using lower and upper bounds of the optimal solution value, the range was refined until its length was within a pre-defined error.

Another problem we studied considered the context in which you must cut the plates purchased in two parts. This problem arises in the context where the original plates are too long and, hence, do not fit in the smaller transportation trucks. Therefore, the plates must be cut into two parts. The two parts need not be identical necessarily but the cut should be made at the same position in all plates. The supplier then offers the client the opportunity to specify where this cutting position of the plates should be. We developed a heuristic that analysed potentially good locations for this cut. These cutting points were determined from the cutting patterns of the solution of the cutting stock problem obtained with the original-sized plates. The cutting points analyzed were a subset of the conical combinations of the lengths of the panels (items) to be cut. 
Details of the results that we reviewed in this section can be obtained in Yanasse, Zinober \& Harris (1991, 1994), Yanasse \& Zinober (1991), Yanasse (1994a).

\subsubsection{Generation of special patterns}

In our research activities, we studied some special patterns that are used in practice. Due to the characteristics of the machine, some cutting patterns require less machine time than others. For example, in the production cutting process of rectangular reconstituted wooden fiber plates, the plates may be rotated to perform the transversal and longitudinal cuttings (guillotine cuts). The cut can be done in several stages, where each stage implies a 90-degree rotation of the object, or part of it, to be cut.

To reduce the loss of material further, more complex patterns can be cut using a larger number of stages. However, these patterns require a larger number of rotations of the plate, increasing the cutting time of the objects. Depending on the situation, it is desirable to use simpler cutting patterns to reduce the cutting time.

Checkerboard patterns, also known as 1-group patterns, belong to a special class of 2-stage patterns and can be produced without the need to cut each strip separately obtained in the first stage, so that only the saw (or object) is rotated 90 degrees after the first stage cut. In Figure 1 a checkerboard pattern cut is illustrated. The strips obtained in the first stage are cut simultaneously in the second stage, producing the requested items.

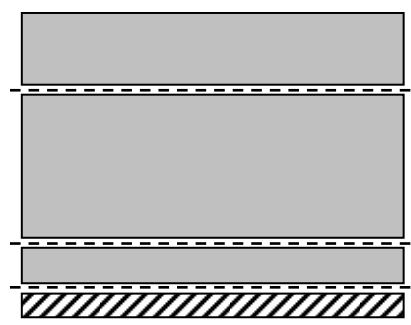

(a)

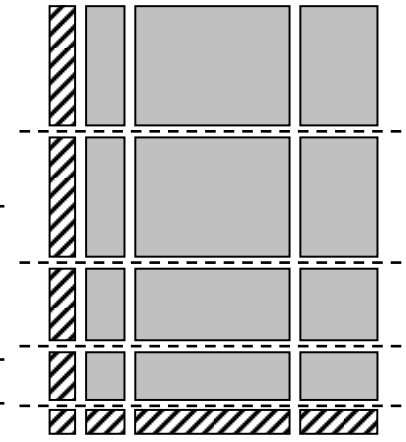

(b)

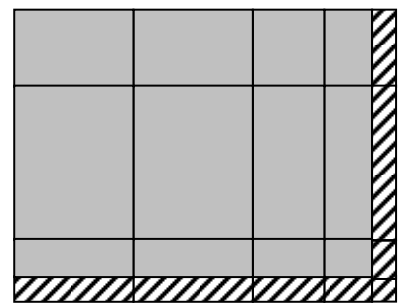

(c)

Figure 1 - Cutting a checkerboard pattern: (a) first cut (first stage), (b) rotation of 90 degrees (second cut, second stage), (c) Checkerboard pattern cut.

Checkerboard patterns require less machine time and are of particular interest in high-demand settings, particularly when the saw machine is a production bottleneck. The checkerboard pattern is exact when all items produced are obtained immediately after the second stage cut. Checkerboard patterns can also be non-exact when there is a need to trim the pieces obtained from the second stage to produce the items requested. In this case, many times, the cut is performed on another machine, possibly a less loaded, simpler model, but certainly incurring additional costs. 
The literature on cutting problems is extensive, but there are few studies dealing specifically with checkerboard pattern generation. We developed an exact enumerative algorithm (to our knowledge, the first) for determining exact checkerboard patterns. This algorithm uses the previous algorithm that we developed for the determination of the $K$-best solutions of the one-dimensional knapsack problem and it is applicable to unconstrained exact checkerboard patterns.

The algorithm has two phases, first, seeking a better combination in the strips and, later, seeking a good combination of strips. With the use of the $K$-best algorithm for the knapsack problem, we could take into consideration additional constraints to the basic knapsack problem without much additional computational effort. This is particularly interesting in cutting environments, because in the solution recovering process, we can take into account whether they meet the additional constraints imposed, and keep only the ones that meet such restrictions. We also developed another enumerative algorithm for the constrained exact case.

In addition, we developed and tested linear and non-linear integer programming models for the exact and non-exact two-stage checkerboard pattern generation problem. They are among the first and among the few models suggested in the literature for the problem. We also developed and tested a linearization of a non-linear formulation of the problem proposed in the literature for the exact checkerboard pattern generation problem. Afterwards we extended the proposed model to deal with 1-group, 2-group, and 3-group patterns. We also developed and tested linear and nonlinear integer programming models for the constrained two-stage guillotine pattern generation problem.

Details of the results that we reviewed in this section can be obtained in Yanasse \& Katsurayama (2004, 2005a,b, 2008), Yanasse \& Morabito (2006, 2008, 2012), Katsurayama \& Yanasse (1999, 2000, 2001a,b, 2004a, 2005), Yanasse, Morabito \& Arenales (2008).

\subsubsection{Reduction in the number of patterns}

In some cutting environments the cutting process or the machine imposes a set up cost each time a different pattern is cut, such as when the positions of the cutting knives need to be adjusted or prepared for each new pattern to be cut. But another common goal is to keep the losses of material as low as possible. These two objectives are often conflicting. The problem can be formulated as follows:

$$
\begin{array}{cc}
\min \left(\sum_{j=1}^{n} c_{j} x_{j}, \sum_{j=1}^{n} \delta\left(x_{j}\right)\right) & \\
\text { subject to } \quad l_{i} \leq \sum_{j=1}^{n} a_{i j} x_{j} \leq b_{i} & i=1,2, \ldots, m \\
x_{j} \in \mathbb{N} & j=1, \ldots, n
\end{array}
$$


where,

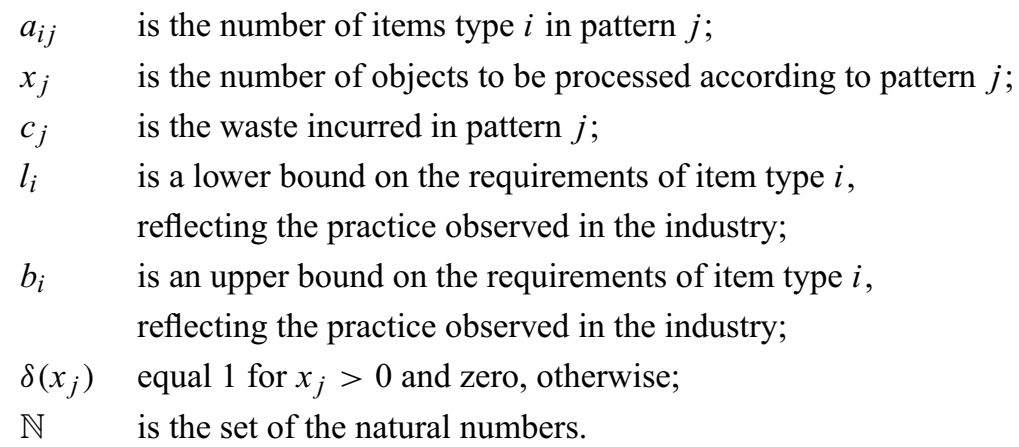

We studied this bi-objective problem and we developed some heuristics to solve it. We showed that determining the least possible number of patterns for any solution to the problem is NP-hard, and we proposed new lower bounds for the minimum number of patterns in this cutting stock problem. We suggested several heuristics for this problem, using the idea of combining high demand items that could be cut with a high frequency in a pattern. The suggested heuristics were tested with one-dimensional instances, but the procedures can be extended in a straightforward way to cope with hgher dimensional cutting stock problems.

We also modified a proposal of the literature to combine patterns, that attempts to reduce the number of distinct patterns, while keeping the total number of objects to be cut. Our modified proposal systematically determines better solutions for the problem compared to the solutions obtained with the original proposal.

Details of the results that we reviewed in this section can be obtained in Yanasse \& Limeira (2003, 2006), Yanasse, Katsurayama \& Limeira (2004), Yanasse (2005), Yanasse \& Cerqueira (2009), Cerqueira \& Yanasse (2009), Yanasse, Poldi \& Cerqueira (2011).

\subsubsection{Reduction in the number of cycles}

Consider a production environment with high demand, where the cutting machine can cut several objects together at a time. If the cutting frequency of a pattern is high, the saw machine can cut up to $C$ objects all together according to this pattern ( $C$ is the capacity of the machine), using a single saw machine cycle. A saw cycle corresponds to the time spent by the cutting machine to cut one or more objects together (up to a maximum of $C$ objects) according to some pattern. It is assumed that the saw cycle does not vary much with the amount of objects being cut together or with the pattern being cut. Therefore, to minimize the machine time it is enough to minimize the number of saw cycles needed to cut all the items demanded.

Initially, we suggested a heuristic to solve this problem of reducing the number of saw cycles. In this heuristic, we sequentially generated patterns that could be cut in multiple quantities of the saw machine capacity $C$ and with a certain level of efficiency in terms of waste. In order to generate such patterns, the demands of the items were divided by this multiple of $C$ and rounded 
down to the nearest integer. By doing this, any item that was included in a pattern could be cut at least this multiple of $C$ times without overproducing any one of the items. If we could not generate any patterns with the minimum efficiency level established and with a frequency that was this multiple of $C$, then the frequency was gradually decreased. The efficiency level was also controlled as the frequency decreased. This was done until the entire demand was satisfied.

We later discussed special cases in which the problem of minimizing the number of saw cycles was equivalent to minimizing the number of distinct cutting patterns. The problems are not equivalent, in general. We observed that, given the similarity between the two problems, an indirect way to minimize the number of saw cycles was to reduce the number of distinct patterns in a cutting plan and vice versa.

We proposed an integer linear programming model to the problem of minimizing the number of saw cycles (to the best of our knowledge, the first in the literature that is linear). This formulation has yet to be explored due to difficulties in its solution. There are a large amount of columns and a column regeneration problem, i.e., using column generation, after relaxing the integrality constraints of the decision variables, the same column keeps being generated in the subproblems.

Details of the results that we reviewed in this section can be obtained in Yanasse, Harris \& Zinober (1993), Ranck Junior, Yanasse \& Becceneri (2008), Yanasse (2008a), Martins, Rangel \& Yanasse (2010).

\subsubsection{Pattern sequencing problems - MOSP}

There may also be a sequencing problem associated with the cutting problem, since the order in which the patterns are cut can influence, for instance, the inventory of the items being cut, the discontinuities in cutting an item type, the number of open stacks formed during the cutting process, etc.

The minimization of the open stacks problem (MOSP) appears, for example, when you have a limited storage capacity around the saw machine and stacks are mounted around the saw, one for each type of item cut. If the number of stacks increases, eventually, some of them will have to be temporarily removed to another storage location to make room for new stacks and, later, they must be brought back to have their requests completed. This is inconvenient because of the extra handling operations and the costs involved. The removal of complete stacks poses no problems since they no longer have to return to the side of the saw machine. We are interested in determining a sequence to cut the patterns, so that the maximum number of open stacks is minimized.

To the best of our knowledge, we were the pioneers in introducing and publishing a work focusing on the MOSP in the context of cutting. We also presented the MOSP in the context of production systems, which occurs when we have the production of an item triggered by a task. Customer orders are composed of different types of items and the production managers want to determine a sequence of the tasks such that the number of incomplete client orders is the smallest possible. 
Incomplete orders imply in a larger amount of items in stock since they cannot be delivered to the clients. A large amount of items in stock creates handling problems, larger inventory costs, a larger amount of capital invested in stock, late billing, etc. Thus, there is great interest in studying the MOSP.

We studied this problem and we developed the first integer linear programming model for the MOSP. As far as we know, we also proposed the first exact enumerative algorithm for its solution. The mathematical model developed is based on the model of the minimization of tool switches problem (see Section 2.3). The MOSP and the minimization of tool switches problem are similar, but they are not equivalent problems. They are equivalent in terms of the optimal solution sequence under certain conditions. Based on this equivalency, a MOSP model was elaborated.

In the MOSP we wanted to determine a permutation of the patterns that indicates the sequence in which they should be cut, so as to minimize the maximum number of open stacks during the cutting process. Instead of determining a permutation of the cutting patterns, we decided to determine an order in which the open stacks were closed, so that the maximum number of open stacks was minimized during the cutting process. In most of our studies, we tried to determine such an order for, under controlled conditions, we showed that this is computationally more efficient. In other words, it is always better or, in the worst case, equal to the enumeration of the permutations of the patterns.

Another contribution we made to solving this problem was its definition as a problem of traversing arcs in a graph. The graph in question, called a MOSP graph, is obtained as follows: to each type of item we have a vertex in the graph; there is an edge connecting two vertices in this graph if, and only if, there is at least one cutting pattern in which the two items appear together.

The MOSP graph has been used to identify some characteristics of optimal solutions to the MOSP that can be explored in the search for a solution. We also derived new lower bounds for the problem, based on the structure of the corresponding MOSP graph. For instance, the smallest degree of a node of the MOSP graph plus one is a lower bound for the optimal solution value of the MOSP; any subgraph of a MOSP graph provides a lower bound for the optimal solution value of the original MOSP; any graph obtained by collapsing an arc of the MOSP graph can be used to determine a lower bound for the optimal solution value of the original MOSP. These results can be applied recursively and still be valid. Similarly, by taking subgraphs to determine lower bounds, we can also delete patterns of the original set of patterns and obtain lower bounds for the optimal value of the original problem using the optimal solution of the MOSP problem composed by a subset of the original set of patterns.

An interesting result we identified is that if two (or more) different instances of the problem, with completely different patterns, generate the same MOSP graph, then these instances are equivalent in terms of determining their optimal solutions. You can find an optimal solution of these instances using the MOSP graph and afterwards, generate an optimal solution corresponding to each one of the original instances. 
From this result we also concluded that a MOSP instance where all patterns have at most two different item types is, solutionwise, as difficult as any other MOSP instance where the patterns have any number of item types. So, the number of item types in the patterns have no influence on in the computational complexity of the problem.

We also used the MOSP graph to propose several pre-processing operations of the data of an instance to reduce its size. We used these operations in some test instances proposed in the literature, and we showed that many of them could be easily solved.

We also proved that MOSP is NP-hard and that it is equivalent to other already known graph problems defined in the literature, in particular, the Gate Matrix Layout Problem that occurs in large scale integrated circuits.

Some heuristics were also developed to determine good upper bound for the MOSP, improvements in exact enumerative methods were suggested, and different mathematical formulations of the problem were defined and tested. Special polynomial cases of MOSP were identified, such as the case when the MOSP graph is a tree, a 1-tree, etc., and polynomial algorithms for their solutions were suggested.

Details of the results that we reviewed in this section can be obtained in Yanasse (1994b, 1996a,b, 1997a,b,c, 1998, 2008b,c), Yanasse, Becceneri \& Soma (1997, 1998a, 1999a, 2002a,b, 2007), Yanasse \& Limeira (2004), Linhares \& Yanasse (1999, 2002a,b), Linhares, Yanasse \& Torreão (1999), Becceneri, Yanasse \& Soma (2002, 2004), Pinto \& Yanasse (2000), Lamosa, Yanasse \& Preto (2001), Yanasse \& Pinto (2003), Yanasse \& Senne (2010), Fink, Munari Jr, Costa \& Yanasse (2010).

\subsubsection{Cutting and pattern sequencing integrated problem}

Cutting stock and pattern sequencing problems have been treated independently in the literature because each one of these problems is, by itself, computationally difficult to solve. But, in certain cases, solving these problems independently may lead to an infeasible solution where it is not possible to sequence the cutting patterns and comply with all existing constraints. For example, when there is a limitation on the maximum number of stacks, the solution of the cuttting stock problem may lead to a large number of open stacks, which could be infeasible in practice.

We studied the cutting and pattern sequencing integrated problem and we developed a heuristic procedure to solve this problem. A solution to the integrated problem consists of a set of patterns with minimum cost and a sequence in which these patterns are to be processed. In this heuristic, we started with a solution to the cutting stock problem and, in the case where the sequencing was infeasible, constraints in the composition of the patterns were imposed. A new solution was thus obtained and when the sequencing was infeasible again, new constraints on the composition of the patterns were enforced. This was done in an iterative manner until a feasible solution was obtained. 
We also developed a mathematical model for the integrated problem (to the best of our knowledge, the first one on the literature). We formulated the integrated problem as an integer linear programming problem and we proposed a solution procedure for its resolution. Using lagrangian relaxation, we decomposed the problem into two subproblems, the cutting stock problem and the pattern sequencing problem. The resulting dual problem was solved, using a modified subgradient method. A heuristic procedure was used to provide a good upper bound for the integrated problem to set the step size in the subgradient method. The cutting stock problem was solved using column generation, after relaxing the integrality constraints of the decision variables. The pattern sequencing problem was solved using an exact algorithm for the MOSP. The limited computational tests performed indicated the usability of the proposed scheme. This is one of the few studies published in the literature that really seeks to solve the problem of generating patterns and sequencing them in a integrated manner.

Details of the results that we reviewed in this section can be obtained in Pinto \& Yanasse (2004, 2005), Yanasse \& Lamosa (2007).

\subsubsection{Usable leftovers}

In some industries, when cutting the objects, the leftovers which are sufficiently large can return to stock to be used later.

We studied the case of the one-dimensional cutting stock problem with usable leftovers. The literature about usable leftovers is scarce and the problem still lacks clear and appropriate definitions. What is a usable leftover? How to compare two different solutions to the cutting problem with usable leftovers? In our paper, we discussed these issues with some proposals. We also adapted some classical heuristics for the cutting stock problem, to take the usable leftovers into account and we simulated their use to evaluate the results.

Details of these studies discussed in this section can be obtained in Cherri, Arenales \& Yanasse $(2007,2009,2012)$.

\subsection{Tool Switches}

Consider a productive environment where you have a set of tasks to be processed in a flexible manufacturing machine. The tool magazine of the machine has a limited capacity and cannot store all the tools simultaneously that are needed to process all the tasks. Therefore, tool exchanges are necessary to process all tasks. The problem of minimizing the number of tool switches (MTSP) consists in determining a sequence to process all the tasks so as to minimize the total number of tool switches.

The MTSP is NP-hard and it has been studied by several authors. In most cases, they suggested heuristics to solve it. As mentioned earlier, the MTSP is similar to MOSP, but they are not equivalent. The MTSP also appears in the context of sequencing the cutting patterns, where we want to minimize the handling of open stacks. 
We proposed some new heuristics and exact methods to solve the MTSP. One method proposed used partial orderings of a subset of conveniently chosen tasks. Afterwards, sequences for the complete set of tasks were determined from these partial orderings, and the best one was kept. We used a complete enumeration, and a partial one to obtain the final sequence. The complete enumerations led us to an optimal solution to the problem; when we used a partial enumeration, we could not guarantee the optimality of the solution found.

The exact method proposed proved to be competitive with the best exact method in the literature. In the computational tests performed the exact method performed better for some sets of instances, but worse in others as compared to results in the literature. The performance of the heuristic with partial enumeration was also good compared to other heuristics found in literature. Observe that, again, similar to what we presented for the MOSP, the optimal solution value of a MTSP defined by any subset of the set of tasks of an instance, say Q, of MTSP provides a lower bound for the optimal solution value of Q.

We also developed a two-phase heuristic to solve the MTSP: a constructive phase, based on the MOSP graph, and an improvement phase, based on an Iterated Local Search. This heuristic presented better perfomance in terms of the quality of the solution compared to the previous heuristics we suggested.

Another exact method we proposed transformed the MTSP into an equivalent generalized travelling salesman problem. This was a new transformation that seems to be interesting for the class of instances of the MTSP where the number of tools required by each task is relatively large compared with the capacity of the tool magazine in the machine. In this case, we found that the number of nodes in the transformed generalized travelling salesman problem did not increase much, being comparable to the number of tasks in the problem.

We also proposed new lower bounds for the MTSP based on the optimal solution value of the corresponding minimization of the open stacks problem. We showed that when we removed a cutting vertex from the MOSP graph of a MTSP and all edges incident to that vertex, an optimal solution for the original problem could be built from optimal solutions of MTSPs corresponding to the connected components of the resulting graph. Using this result, we were able to develop polynomial algorithms for special classes of MTSP instances such as occurs when the corresponding MOSP graph of an instance is a tree.

Details of the results that we discussed in this section can be obtained in Yanasse, Olivo \& Vijaykumar (1995), Yanasse, Vijaykumar \& Olivo (1996), Pinto \& Yanasse (2001), Yanasse \& Pinto (2002), Yanasse \& Lamosa (2006a,b), Yanasse (2007, 2009, 2011, 2012), Yanasse, Rodrigues \& Senne (2009), Yanasse, Senne \& Rodrigues (2008a,b), Senne \& Yanasse (2009), Chaves, Senne \& Yanasse $(2010,2012)$.

\subsection{Production/Project scheduling}

Roughly speaking, in production scheduling, we seek the best allocation of resources in time to perfom tasks, according to some pre-determined criteria. In project scheduling we have activities 
that need to be performed, according to pre-established precedence relationships, so that a project is completed. We seek the best execution of the activities for the conclusion of the project, taking into account pre-determined objectives and additional constraints such as budget limitations.

We developed mixed integer programming models to establish a production schedule in an assembly fixture workstation of an aeronautical industry, where the jobs have adjacency constraints. These models provided better quality solutions than those used in practice. We also determined the computational complexity of some specific production and project scheduling problems, like the CPM problem with non-convex cost functions, or the CPM problem with piecewise linear functions.

Details of the results that we discussed in this section can be obtained in Contador \& Yanasse (1989a,b), Yanasse \& Contador (1989, 1991), Silva, Morabito \& Yanasse (2010, 2011), Silva, Morabito, Yamashita \& Yanasse (2012).

\section{CONCLUDING REMARKS}

We have reviewed some of the results we have derived over the past 30 years, studying some optimization problems that involved actual problems arising in industrial settings. In the future, we intend to continue pursuing the elaboratation and the solution of mathematical decision models that may help decision makers to better understand complex systems. We plan to continue addressing problems from industrial cutting environments and also problems from other contexts, either because they present similarities or because they are integrated with cutting problems we have been focusing.

For instance, future research on the generation of special patterns might include the study of patterns for the compartmentalized knapsack problem. A simple idea to pursue is to develop a heuristic where we consider only the combination of the most valuable items in each compartment. To generate the most valuable compartments, we could use the algorithm we developed for the k-best solution of one-dimensional knapsack problem. Another possibility to explore is to study the linear model we developed for this problem and verify up to what size it can be used to solve the problem. In addition, we can try to explore its mathematical structure, to be able to solve larger instances.

We plan to study the problem of reducing the number of different patterns and the problem of reducing the number of saw cycles further. In the problem of reducing the number of distinct patterns, we can explore the pre-existing theory of the simplex method for solving linear programming problems. For example, if we use the model proposed by Gilmore and Gomory (1961) for the cutting stock problem and solve the linear problem associated with it, we can think about aggregating constraints of this model. With fewer constraints, the number of basic variables in the optimal solution of the problem decreases, i.e. the number of distinct patterns in the solution decreases. The difficulty consists in determining a way to aggregate constraints so that the solution to the problem does not lose much in quality. For the problem of reducing the number of machine cycles, we can explore the linear model we developed, trying to find an efficient way to solve it. As already mentioned, there are difficulties in using the associated relaxed 
linear program, since there are many linearly dependent columns that cannot be simultaneously in a base when using the simplex method to solve the model. We could also develop a procedure that attempts to explore the similarity of this problem with the reduction of distinct patterns.

For the minimization of tool switches problem, we can explore the idea of aggregating simple tasks, that is, tasks that require a small number of tools. As a consequence, we could reduce the size of the instance and, hopefully, we would require a lower computational effort to solve the problem. The challenge is to define the aggregation procedure so that the solution of the modified instance is also optimal for the original one.

There are cases where the aggregation of tasks is not possible simply because there are no simple tasks in the instance. In these cases, we plan to verify whether the transformation of the minimization of tool switches problem in a generalized traveling salesman problem would not be an interesting alternative to be explored, since the number of nodes of the transformed problem does not grow much in these cases.

We also intend to develop a decomposition procedure that reduces the original instance into a set of smaller-sized instances. The way we plan to decompose the problem is by duplicating tools.

Another problem we have started studying is the packing of items in a multi-compartmentized truck with the objective of minimizing the handling of the cargo along the delivery route. For this multi-compartmentized vehicle loading problem, we now intend to take into account load balancing constraints and fragility. An idea to explore is the possibility of shelf loading in each compartment.

These are some of our future research plans. We hope to be able to contribute to the improvement of some production processes to contribute a little to the consolidation of research groups in this area as well as in related areas, and to promote scientific and technological development as well as the training of human resources in the field of operations research.

\section{ACKNOWLEDGMENTS}

Many of the results derived were obtained in collaboration with colleagues from many places and universities, graduate students, and my thesis advisor, Professor Gabriel Bitran. I must thank all of them for their discussions, support, advise, and friendship. I must also acknowledge the financial support received from CNPq, CAPES and FAPESP.

\section{REFERENCES}

[1] Becceneri JC, Yanasse HH \& Soma NY. 2002. A method for solving the minimisation of the maximum number of open stacks problem. CLAIO' 2002, Concepción, Chile. Published in CD (Acta de Trabajos), ref. A37N09.

[2] Becceneri JC, Yanasse HH \& Soma NY. 2004. A method for solving the minimisation of the maximum number of open stacks problem within a cutting process. Computers and Operations Research, 31(14): 2315-2332. ISSN: 0305-0548. DI 10.1016/S0305-0548(03)00189-.

[3] Bellman RE. 1956. Dynamic Programming, Princeton University Press, Princeton, 1957. 
[4] Bitran GR, Magnanti TL \& Yanasse HH. 1982a. Analysis of the uncapacitated dynamic lot size problem. ORSA/TIMS meeting, San Diego, CA, EUA. (Published by INPE, ref. INPE-2472PRE/161).

[5] Bitran GR, Magnanti TL \& YAnasse HH. 1982b. Análise de alguns procedimentos heurísticos para problemas de tamanho de lote não-capacitado. XV Simpósio Brasileiro de Pesquisa Operacional/I Congresso Latino-Americano de Pesquisa Operacional e Engenharia de Sistemas, Rio de Janeiro-RJ. Published in the proceedings (Published by INPE, ref. INPE-2423-PRE/130).

[6] Bitran GR, Magnanti TL \& Yanasse HH. 1984a. Approximation methods for the uncapacitated lot size problem. Management Science, 30(9): 1121-1140. DI 10.1287/mnsc.30.9.1121.

[7] Bitran GR, Magnanti TL \& Yanasse HH. 1984b. Desempenho, no pior caso, de algumas heurísticas para problemas de tamanho de lote. XVII Simpósio Brasileiro de Pesquisa Operacional, Rio de Janeiro, RJ. Published in the proceedings. (Published by INPE, ref. INPE- 3134-PRE/525).

[8] BitRAn GR \& YANASSE HH. 1982. Computational complexity of the capacitated lot size problem. Management Science, 28(10): 1174-1186. (Sloan WP No. 1271-81, November 1981) (Published by INPE, ref. INPE-2382-RPE/410). doi: 10.1287/mnsc.28.10.1174.

[9] Bitran GR \& YANASSE HH. 1984. Deterministic approximations to stochastic production problems. Operations Research, 32(5): 999-1018. ORSA/TIMS meeting-San Diego, CA, EUA, 1982. (Published by INPE, ref. INPE-2861-RPE/398). DI 10.1287/opre.32.5.999.

[10] Cerqueira GRL \& YANASSE HH. 2009. A pattern reduction procedure in a one-dimensional cutting stock problem by grouping items according to their demands. Journal of Computational Interdisciplinary Sciences, 1(2): 159-164. ISSN 1983-8409.

[11] Chaves AA, Senne ElF \& Yanasse HH. 2010. Uma nova heuristica para o problema de minimização de trocas de ferramentas. XLII Simpósio Brasileiro de Pesquisa Operacional, Bento Gonçalves, RS. Proceedings of the XLII SBPO, in CD, file 72227.pdf., p. 1549-1560, ISSN 15181731.

[12] Chaves AA, Senne ElF \& Yanasse HH. 2012. Uma nova heurística para o problema de minimização de trocas de ferramentas. Gestão \& Produção, 19(1): 1-14.

[13] Cherri AC, Arenales MN \& Yanasse HH. 2007. Resolution of the unidimensional cutting stock problem with usable leftover. ICORD VI, Fortaleza, CE. Proceedings of the ICORD VI, in CD, arq0045, p. 506-517.

[14] Cherri AC, Arenales MN \& Yanasse HH. 2009. The one-dimensional cutting stock problem with usable leftovers - a heuristic approach. European Journal of Operational Research, 196(3): 897-908. ISSN: 0377-2217. doi: 10.1016/j.ejor.2008.04.039.

[15] Cherri AC, Arenales MN \& Yanasse HH. 2012. The usable leftover one-dimensional cutting stock problem - a priority in use heuristic. Accepted, International Transactions in Operational Research, 2012.

[16] Contador JL, Gartenkraut M \& Yanasse HH. 1984. Um sistema de planejamento agregado de estoques. III ENEGEP - São Paulo. (Published by INPE, ref. INPE-2766-PRE/339).

[17] CONTADOR JL \& YANASSE HH. 1983. Sistemas de planejamento hierárquico aplicado à produção: um estudo. IV Seminário ADUNESP - Guaratinguetá. (Published by INPE, ref. INPE-3147PRE/153-06/84). 
[18] Contador JL \& YANASSE HH. 1989a. O problema CPM com investimento. $8^{\circ}$ Encontro Nacional de Engenharia de Produção, Porto Alegre, RS. (Published in the Proceedings, vol. 2, p. 221-239).

[19] Contador JL \& YANAsSe HH. 1989b. Um procedimento para minimizar o número de iterações do algoritmo de preservação de fluxo para o problema CPM. XXII SBPO, Simpósio Brasileiro de Pesquisa Operacional, Fortaleza, CE. (Published in the Proceedings, p. 380-385).

[20] Fink C, Munari JR P, Costa AM \& Yanasse HH. 2010b. Uma estratégia de solução para o problema de minimização do número máximo de pilhas abertas utilizando o problema do caixeiro viajante - Notas do ICMC - Série Computação, no. 95, Universidade de São Paulo, Instituto de Ciências Matemáticas e de Computação, São Carlos, SP. ISSN 0103-2577, 16 p.

[21] GILMORE PC \& GOMORY RE. 1961. A linear programming approach to the cutting-stock problem. Operations Research, 9: 848-859.

[22] HiRATA CM \& YANASSE HH. 1983. Medição de erros de uma aproximação determinística para um problema de planejamento de produção estocástico. XVI Simpósio Brasileiro de Pesquisa Operacional - Florianópolis, SC. Published in the proceedings. (Published by INPE, ref. INPE-2768PRE/341).

[23] Horowitz E \& SAHNi S. 1974. Computing partitions with applications to the knapsack problem. J. ACM, pp. 277-292.

[24] Katsurayama DM \& Yanasse HH. 1999. Um algoritmo enumerativo para determinação de padrões tabuleiro. XXXI Simpósio Brasileiro de Pesquisa Operacional, Juiz de Fora, MG. Published in the proceedings in $\mathrm{CD}$.

[25] Katsurayama DM \& YAnasse HH. 2000. Um algoritmo enumerativo para determinação de padrões tabuleiros: aspectos computacionais de implementação. XXXII SBPO - Simpósio Brasileiro de Pesquisa Operacional, Viçosa, MG. Published in the proceedings in CD, p. 370-382.

[26] Katsurayama DM \& Yanasse HH. 2001a. Uma análise de produtividade do equipamento de cortes utilizando-se padrões tabuleiro. XXI ENEGEP - Encontro Nacional de Engenharia de Produção/VII International Conference on Industrial Engineering and Operations Management, Salvador, BA. Abstract, p. 86. Published in CD-ROM, ISBN 85.88478-02-1. V Oficina Nacional de Problemas de Corte \& Empacotamento, São José dos Campos, SP, 2001. Proceedings of the V Oficina, p. 01-18.

[27] Katsurayama DM \& Yanasse HH. 2001b. Análise de produtividade de uma serra com o uso de padrões 2-estágios especiais. XXXIII SBPO - Simpósio Brasileiro de Pesquisa Operacional, Campos de Jordão, SP. Published in CD-ROM, p. 1138-1145.

[28] KATSURAYAma DM \& YANASSE HH. 2004. Um algoritmo para geração de padrões tabuleiros exatos a partir de uma combinação dada de itens. XXXVI Simpósio Brasileiro de Pesquisa Operacional, São João Del Rei, MG. Proceedings of the XXXVI Simpósio Brasileiro de Pesquisa Operacional, in CD-ROM, ref. arq0098, p. 1637-1648.

[29] KATSurayama DM \& YANASSE HH. 2005. Algoritmos para determinação de padrões tabuleiros exatos e restritos: testes computacionais comparativos. XXXVII Simpósio Brasileiro de Pesquisa Operacional, Gramado, RS. Proceedings of the XXXVII Simpósio Brasileiro de Pesquisa Operacional, in CD-ROM, p. 1567-1578.

[30] Lamosa DM, Yanasse HH \& Preto AJ. 2001. Proposta de uma implementação paralela de um algoritmo para a resolução de um problema de seqüenciamento de padrões de corte. XXXIII 
SBPO - Simpósio Brasileiro de Pesquisa Operacional, Campos de Jordão, SP. Published in CDROM, p. 1236-1240. V Oficina Nacional de Problemas de Corte \& Empacotamento, São José dos Campos, SP. Proceedings of the V Oficina, p. 258-263.

[31] Lima G \& YANASSE HH. 1985. Planejamento agregado com modelos matemáticos: uma experiência prática. XVIII Simpósio Brasileiro de Pesquisa Operacional, S.J. Campos, SP. Published in the proceedings. (Published by INPE, ref. INPE-3547-PRE/74 - June 1985).

[32] Lima G \& Yanasse HH. 1986. Planejamento agregado: o caso de uma indústria aeronáutica. São José dos Campos, INPE. (Published by INPE, ref. INPE-3827-PRE/903).

[33] Linhares A \& YANASSE HH. 1999. On the minimization of open stack problem. Technical Report, ref. LAC-002/99, pp. 01-18, São José dos Campos, SP, Brasil.

[34] Linhares A \& YANASSE HH. 2002a. Industrial pattern-sequencing problems: some complexity results and new local search models. Concurso de Teses e Dissertações - Teses de Doutorado, CTD 2002, SBC, Proceedings of the XXII Congresso da Sociedade Brasileira de Computação, p. 550-557, in CR-ROM. INPE-9375-PRE/5035.

[35] Linhares A \& YANASSE HH. 2002b. Connections between cutting-pattern sequencing, VLSI design, and flexible machines. Computers and Operations Research, 29(12): 1759-1772. ISSN: 03050548. DI 10.1016/S0305-0548(01)00054-5.

[36] Linhares A, YANASSE HH \& TORREÃo JRA. 1999b. Linear gate assignment: a fast statistical mechanics approach. IEEE Transaction on Computer Aided Design of Integrated Circuits and Systems, 18(12): 1750-1758. DI 10.1109/43.811324.

[37] Maculan N, Soma NY \& Yanasse HH. 1996. A partial representation technique for subset sums. XXVIII Simpósio Brasileiro de Pesquisa Operacional / VIII Latin-Iberian-American Congress on Operations Research and System Engineering, Rio de Janeiro, RJ. Extended abstract published, Vol. III. 1127-1131.

[38] Martins AT, RANGel MSN \& YANASSE HH. 2010. Um algoritmo para a redução de ciclos da serra e de objetos no problema de corte de estoque bidimensional de uma indústria moveleira. XLII Simpósio Brasileiro de Pesquisa Operacional, Bento Gonçalves, RS. Proceedings of the XLII SBPO (in CD), p. 2030-2041, ISSN 1518-1731, in CD, file 69270.

[39] Peterson R \& Silver EA. 1979. Decision Systems for Inventory Management and Production Planning, Wiley, New York.

[40] Pinto MJ \& YAnAsse HH. 2000. Uma variação do problema de minimização de pilhas abertas. XXXII SBPO - Simpósio Brasileiro de Pesquisa Operacional, Viçosa, MG. Published in CD, p. $383-388$.

[41] Pinto MJ \& YANAsse HH. 2001. O problema de minimização de trocas de ferramentas: propostas para a sua resolução. XXXIII SBPO - Simpósio Brasileiro de Pesquisa Operacional, Campos de Jordão, SP. Published in CD, p. 1410-1419.

[42] Pinto MJ \& YAnasse HH. 2004. Uma heurística para resolução do problema de corte integrado ao problema de seqüenciamento dos padrões, XXXVI Simpósio Brasileiro de Pesquisa Operacional, São João Del-Rei, MG. Proceedings of the XXXVI Simpósio Brasileiro de Pesquisa Operacional, in CD, ref. arq0085, p. 1534-1545. 
[43] Pinto MJ \& Yanasse HH. 2005. Resolução do problema de corte integrado ao problema de seqüenciamento dos padrões utilizando relaxação lagrangiana, XXXVII Simpósio Brasileiro de Pesquisa Operacional, Gramado, RS. Proceedings of the XXXVII Simpósio Brasileiro de Pesquisa Operacional, in CD-ROM, p. 1744-1755.

[44] RANCK Junior R, YAnasse HH \& Becceneri JC. 2008c. Uma heurística para o problema de redução de ciclos de serra. XL Simpósio Brasileiro de Pesquisa Operacional, João Pessoa, PB. Published in the proceedings (in CD) of the XL SBPO, arq0022, p. 1935-1941. ISSN 1518-1731.

[45] Sanches CAA, Soma NY \& YAnasse HH. 2001. Algoritmos paralelos para o problema da mochila. V Oficina Nacional de Problemas de Corte \& Empacotamento, São José dos Campos, SP. Proceedings of the V Oficina, p. 184-192.

[46] SANChes CAA, Soma NY \& YANASSE HH. 2002. Comments on parallel algorithms for the knapsack problem. Parallel Computing, 28(10): 1501-1505. (Short Communication). DI 10.1016/S01678191(02)00150-3.

[47] SANChes CAA, Soma NY \& YANASSE HH. 2007. An optimal and scalable parallelization of the two-list algorithm for the subset-sum problem. European Journal of Operational Research, 176(2): 870-879. ISSN: 0377-2217. DI 10.1016/j.ejor.2005.09.026.

[48] Sanches CAA, Soma NY \& Yanasse HH. 2008. Parallel Time and Space Upper-Bounds for the Subset-Sum Problem. Theoretical Computer Science, 407: 342-348. ISSN: 0304-3975. doi: 10.1016/j.tcs.2008.06.051, 2008.

[49] Sanches CAA, Soma NY \& YAnAsse HH. 2010. Observations on optimal parallelizations of two-list algorithm. Parallel Computing (Short Communication), 36: 65-67. ISSN: 0167-8191. doi: 10.1016/j.parco.2009.09.005.

[50] Senne ELF \& Yanasse HH. 2009. Beam Search Algorithms for Minimizing Tool Switches on a Flexible Manufacturing System. In: XI WSEAS International Conference on Mathematical and Computational Methods in Science and Engineering, MACMESE'09, Baltimore, MD. Proceedings of the MACMESE'09. Baltimore, EUA: WSEAS Press, v. 1. p. 68-72. ISSN/ISBN: 9789604741335.

[51] Silva BJV, Morabito R \& Yanasse HH. 2010. Programação da produção de montagens em gabaritos com restrições de adjacência na indústria aeronáutica. XLII Simpósio Brasileiro de Pesquisa Operacional, Bento Gonçalves, RS. Proceedings of the XLII SBPO, p. 1110-1120, ISSN 1518-1731, Published in CD, file 72224.pdf.

[52] Silva BJV, Morabito R \& Yanasse HH. 2011. Programação da Produção de Gabaritos de Montagem com Restrições de Adjacência na Indústria Aeronáutica. Produção, 21(4): 696-707. doi: 10.1590/S0103-65132011005000055.

[53] Silva BJV, Morabito R, Yamashita DS \& Yanasse HH. 2012. Production scheduling of assembly fixtures in the aeronautical industry. Submitted.

[54] SOMA NY \& YANASSE HH. 1985. Um algoritmo pseudopolinomial para equações diofantinas lineares. $8^{\circ}$ Congresso Nacional de Matemática Aplicada e Computacional, Florianópolis, SC. Published in the proceedings. (Published by INPE, ref. INPE-3687-PRE/834 - Out. 85).

[55] Soma NY \& YANASSE HH. 1986. Um melhoramento do limitante para o problema de Frobenius da equação diofantina linear. $9^{\circ}$ Congresso Nacional de Matemática Aplicada e Computacional, Brasília-DF. Published in the proceedings. 
[56] SOMA NY \& YANASSE HH. 1987a. Um algoritmo exato pseudopolinomial para a equação diofantina linear 0-1. X Congresso Nacional de Matemática Aplicada e Computacional, Gramado, RS. Published in the proceedings.

[57] SOMA NY \& YANASSE HH. 1987b. A planar solution procedure for linear diophantine equations. ORSA/TIMS - St.Louis meeting, St. Louis, MO, EUA. (Published by INPE, ref. INPE-4205PRE/1082).

[58] Soma NY, Zinober ASI, Yanasse HH \& Harley PJ. 1995. A polynomial approximation scheme for the subset sum problem. Discrete Applied Mathematics, 57: 243-253. DI 10.1016/0166218X(94)00106-N.

[59] YANASSE HH. 1981. Aggregation and computational complexity of lot size problems. Unpublished doctoral dissertation, MIT, Sloan School of Management, Set. 81.

[60] Yanasse HH. 1987. Tamanho de lote: considerações sobre o horizonte de planejamento no caso de um aumento no custo de aquisição. XX SBPO, Simpósio Brasileiro de Pesquisa Operacional, Salvador, BA. Published in the proceedings, p. 132-148. (Published by INPE, ref. INPE-4204PRE/1085).

[61] YANASSE HH. 1990. EOQ systems: the case of an increase in purchase cost. Journal of the Operational Research Society, 41(7): 633-637. DI 10.1057/jors.1990.87.

[62] YANASSE HH. 1994a. A search strategy for the one-size assortment problem. European Journal of Operational Research, 74: 135-142. ISSN: 0377-2217. DI 10.1016/0377-2217(94)90211-9. (Published by INPE, ref. INPE-5489-PRP/177). XXV Simpósio Brasileiro de Pesquisa Operacional, Campinas, 1993. Short version published in the proceedings of the XXV SBPO, p. 297-300.

[63] YANASSE HH. 1994b. On a pattern sequencing problem in the wood industry. TIMS XXXII, Anchorage, Alaska. XXVI Simpósio Brasileiro de Pesquisa Operacional (SBPO), Florianópolis, SC. Proceedings, p. 302-307.

[64] YANASSE HH. 1996a. A heuristic procedure for solving a pattern sequencing problem in the wood cut industry. XVI Encontro Nacional de Engenharia de Produção - ENEGEP/Second International Congress in Industrial Engineering, Piracicaba, SP. Published in the Proceedings (in CD).

[65] YANASSE HH. 1996b. Minimization of open orders - polynomial algorithms for some special cases. Pesquisa Operacional, 16(1): 1-26. XXVII Simpósio Brasileiro de Pesquisa Operacional, Vitória, ES, 1995. (Abstract published). (Technical Report, ref. LAC-007/96, pp. 1-21, São José dos Campos, SP, Brasil).

[66] YANASSE HH. 1997a. On a pattern sequencing problem to minimize the maximum number of open stacks. European Journal of Operational Research, 100: 454-463. ISSN: 0377-2217. DI 10.1016/S0377-2217(97)84107-0. (Technical Report, ref. LAC-007/95, pp. 1-21, São José dos Campos, SP, Brasil).

[67] YANASSE HH. 1997b. A transformation for solving a pattern sequencing problem in the wood cut industry. Pesquisa Operacional, 17(1): 57-70. (Technical Report, ref. LAC-006/96, pp. 1-15, São José dos Campos, SP, Brasil).

[68] YANASSE HH. 1997c. An exact algorithm for the tree case of the minimization of open orders problem. XXIX Simpósio Brasileiro de Pesquisa Operacional (SBPO), Salvador, BA. (Technical Report, ref. LAC-001/97, São José dos Campos, SP, Brasil). 
[69] YANASSE HH. 1998. A note on generating solutions of a pattern sequencing problem to minimize the maximum number of open orders. Technical Report, ref. LAC-002/98, pp. 01-05, São José dos Campos, SP, Brasil.

[70] YANASSE HH. 2005. Propostas para se determinar soluções para o problema de corte de estoques com um número reduzido de padrões, VIII Simpósio de Pesquisa Operacional e Logística da Marinha, Rio de Janeiro, RJ.

[71] YANASSE HH. 2007. Limitante inferior para o problema de minimizar o número de trocas de ferramentas, XXXIX Simpósio Brasileiro de Pesquisa Operacional, Fortaleza, CE. Proceedings of the XXXIX SBPO, in CD, arq0170, p. 1886-1892.

[72] YANASSE HH. 2008a. A note on the minimization of the number of cutting cycles problem. SPOLM 2008, XI Simpósio de Pesquisa Operacional e Logística da Marinha, Rio de Janeiro, RJ. Published in CD, ISSN 1806-3632, file 012.

[73] Yanasse HH. 2008b. Pre-processing operations for the minimization of open stacks problem, XL Simpósio Brasileiro de Pesquisa Operacional, João Pessoa, PB. Published in the proceedings (in CD), arq0249, p. 1780-1789. ISSN 1518-1731.

[74] YANASSE HH. 2008c. Reducing symmetries in the minimization of open stacks problem, CLAIO 2008 - XIV Congreso Latino Ibero Americano de Investigación de Operaciones, Cartagena de Índias, Colombia. Published in CD, file CLAIO_2008_162.

[75] YANASSE HH. 2009. Um novo limitante inferior para o problema de minimização de trocas de ferramentas - XLI Simpósio Brasileiro de Pesquisa Operacional, Porto Seguro, BA. Proceedings in CD, p. 2841-2848, ISSN/ISBN: 15181731 .

[76] YANASSE HH. 2011. Sobre o problema de minimização de trocas de ferramentas: um caso especial. XLIII Simpósio Brasileiro de Pesquisa Operacional, Ubatuba, SP. Proceedings of the XLIII SBPO, p. 2117-2124, in CD.

[77] YANASSE HH. 2012. Um algoritmo polinomial para o caso de árvores do problema de minimização de trocas de ferramentas. XVI CLAIO/XLIV SBPO, Rio de Janeiro, RJ. Abstract Book, p. 107.

[78] Yanasse HH, BecCeneri JC \& SOMA NY. 1997. A collapsing arc heuristic for solving a patterns sequencing problem. EURO XV - INFORMS XXXIV, Barcelona, Spain. $17^{\circ}$ Encontro Nacional de Engenharia de Produção/3 ${ }^{\text {rd }}$ International Congress of Industrial Engineering, Gramado, RS. Published in the proceedings (in $\mathrm{CD}$ ).

[79] Yanasse HH, BeCCENERI JC \& Soma NY. 1998. Um algoritmo exato para um caso especial do problema de sequenciamento de padrões. XXX SBPO, Curitiba, PR. III Oficina Nacional de Problemas de Corte \& Empacotamento with the title "An exact algorithm for a special case of a patterns sequencing problem”, Proceedings of the III Oficina, p. 53-61.

[80] Yanasse HH, BeCCEneri JC \& Soma NY. 1999. Bounds for a problem of sequencing patterns. Pesquisa Operacional, 19(2): 249-277.

[81] Yanasse HH, BecCeneri JC \& Soma NY. 2002a. Ordenamento parcial para reduzir o espaço de busca de uma solução ótima para um problema de seqüenciamento de padrões. XXXIV Simpósio Brasileiro de Pesquisa Operacional, Rio de Janeiro, RJ. Proceedings of the XXXIV Simpósio Brasileiro de Pesquisa Operacional, in CD-ROM, ref. arq0104. 
[82] Yanasse HH, Becceneri JC \& Soma NY. 2002b. A heuristic to solve a pattern sequencing problem based on partial orderings. XXII Encontro Nacional de Engenharia de Produção/VIII International Conference on Industrial Engineering and Operations Management, Curitiba, PR. Technical and Organizational Integration of Supply Chains - Proceedings of the VIII International Conference on Industrial Engineering and Operations Management, Curitiba, Paraná, Brazil, Published by ABEPRO, p. 105-111.

[83] YANASSE HH, BeCCENERI JC \& SOMA NY. 2007. Um algoritmo exato com ordenamento parcial para solução de um problema de programação da produção: experimentos computacionais. Gestão \& Produção, 14(2): 353-361. ISSN 0104-530x.

[84] Yanasse HH \& Cerqueira GRL. 2009. Uma heuristica baseada em geração sequencial de padrões para o problema de corte de estoque unidimensional com um número reduzido de padrões. Gestão \& Produção, 16(2): 200-208. ISSN 0104-530x.

[85] YAnasse HH \& CONTAdor JL. 1989. Prova de que o problema CPM com custo linear por partes é NP-difícil. X Seminário ADUNESP, Guaratinguetá, SP. (Published in the Proceedings, p. 434-439).

[86] Yanasse HH \& CONTAdor JL. 1991. A complexidade do problema CPM com função de custo não-convexa. Investigación Operativa, 2(2): 121-125.

[87] YANASSE HH, HARRIS RG \& ZINOBER ASI. 1993. Uma heurística para redução do número de ciclos da serra no corte de chapas. XIII ENEGEP - Encontro Nacional de Engenharia de Produção/I Congresso Latino Americano de Engenharia Industrial, Florianópolis, SC. Published in the proceedings of the XIII ENEGEP, Florianópolis, Universidade Federal de Santa Catarina, 1993. Vol. II, p. 879-885.

[88] Yanasse HH, Hoto R, Spolador FL \& Arenales MN. 2005. Um modelo linear para o problema da mochila compartimentada. IX Oficina Nacional de Problemas de Corte e Empacotamento, São José dos Campos, SP. Programme \& Abstracts, p. 29.

[89] YANASSE HH \& KATSURAYAMA DM. 2004. Um algoritmo de enumeração implícita para geração de padrões tabuleiros exatos restritos. SPOLM, VII Simpósio de Pesquisa Operacional da Marinha/ VIII Simpósio de Logística da Marinha, Rio de Janeiro, RJ. Published in CD, arq. 0022, ISSN18063632, p. 433-443.

[90] YAnAsse HH \& Katsurayama DM. 2005a. Checkerboard patterns: proposals for its generation. International Transactions in Operations Research, 12: 21-45.

[91] Yanasse HH \& Katsurayama DM. 2005b. A new algorithm to generate constrained exact checkerboard patterns. XXV Encontro Nacional de Engenharia de Produção/X International Conference on Industrial Engineering and Operations Management, Porto Alegre, RS, Abstracts p. 189, Proceedings of the X International Conference on Industrial Engineering and Operations Management, entitled "New research directions in industrial engineering: integrating theory and practice", edited by LeÃo AG, Fogliatto FS, Cortimiglia MC, Carvalho MM \& Selig PM; p. 137-144, ISBN 85-88478-17-X. File ICEOM0601-0326, p. 2925-2932, CD of ENEGEP 2005, ISBN 85-88478-15-3.

[92] Yanasse HH \& Katsurayama DM. 2008. An enumeration scheme to generate constrained exact checkerboard patterns. Computers \& Operations Research, 35: 2114-2128. ISSN: 0305-0548. doi: 10.1016/j.cor.2006.10.018.

[93] Yanasse HH, Katsurayama DM \& Limeira MS. 2004. Reducing the number of different patterns in cutting stock problems: new contributions. XXIV Encontro Nacional de Engenharia de 
Produção/X International Conference on Industrial Engineering and Operations Management, Florianópolis, SC. Proceedings of the X International Conference on Industrial Engineering and Operations Management, entitled "Knowledge engineering and management applied for the development of productive systems", edited by Fogliatto FS, Ribeiro JLD, Abreu AF \& Bornia AC; p. 123-130. File ICEOM0601-1333, p. 2982-2989, CD of ENEGEP 2004, ISBN 85-88478-11-0.

[94] Yanasse HH \& Lamosa MJP. 2006a. On solving the minimization of tool switches problem using graphs. XXVI Encontro Nacional de Engenharia de Produção/XII International Conference on Industrial Engineering and Operations Management, Fortaleza, CE. Proceedings in CD, ref. TI460314_6826.pdf, 9pg. ISBN 85-88478-21-8.

[95] YANASSE HH \& LAmOSA MJP. 2006b. A modified enumeration scheme to solve the minimization of tool switches problem. XIII CLAIO - Conferencia Latino-Ibero-Americana de Investigación de Operaciones, Montevidéu, Uruguai. Anales del XIII CLAIO - Conferencia Latino-Ibero-Americana de Investigación Operativa, ISBN 9974-7699-9-X, in CD.

[96] YANASSE HH \& LAMOSA MJP. 2007. An integrated cutting stock and sequencing problem. European Journal of Operational Research, 183(3): 1353-1370, ISSN: 0377-2217. DI 10.1016/ j.ejor.2005.09.054.

[97] YANASSE HH \& Limeira MS. 2003. Algumas heurísticas para redução do número de padrões distintos em problemas de corte de estoques. VI Simpósio de Pesquisa Operacional da Marinha/VII Simpósio de Logística da Marinha, Rio de Janeiro, RJ, 2003. Proceedings of the SPOLM 2003, p. $92-104$.

[98] YANASSE HH \& LimeiRA MS. 2004. Refinements on an enumeration scheme for solving a pattern sequencing problem. International Transactions in Operations Research, 11: 277-292.

[99] YANASSE HH \& Limeira MS. 2006. A hybrid heuristic to reduce the number of different patterns in cutting stock problems. Computers and Operations Research, 33(9): 2744-2756. ISSN: 0305-0548. DI 10.1016/j.cor.2005.02.026.

[100] YAnASSE HH \& MoRABito R. 2006. Linear models for one-group two-dimensional guillotine cutting problems. International Journal of Production Research, 44(17): 3471-3491. Print ISSN: 0020-7543; Online ISSN: 1366-588X. DI 10.1080/00207540500478603.

[101] YAnASSE HH \& MoRABito R. 2008. A note on linear models for two-group and three-group two-dimensional guillotine cutting problems. International Journal of Production Research, 46(21): 6189-6206. doi: 10.1080/00207540601011543. Print ISSN: 0020-7543; Online ISSN: 1366-588X.

[102] YAnAsse HH \& Morabito R. 2012. Modelos lineares e não-lineares inteiros para problemas de corte bidimensionais guilhotinados restritos de dois estágios, Accepted in Produção.

[103] Yanasse HH, Morabito R \& Arenales MN. 2008. Linear and non-linear models for one-, two- and three-group and two-stage two-dimensional guillotine cutting problems. In "Intelligent Decision Support - Current Challenges and Approaches" edited by Andreas Bortfeldt, Jörg Homberger, Herbert Kopfer, Gisether Pankratz, Reinhard Strangmeier, Gabler-Verlag, 2008, p. 69-88.

[104] Yanasse HH, Olivo AA \& ViJaykumar NL. 1995. Uma heuristica para resolver o problema de minimização de trocas de ferramentas em uma máquina de manufatura flexível. XV Encontro Nacional de Engenharia de Produção - ENEGEP/First International Congress in Industrial Engineering, São Carlos, SP. Published in the proceedings, Vol. III, p. 1397-1401. 
[105] Yanasse HH \& Pinto MJ. 2002. The minimization of tool switches problem as a network flow problem with side constraints. XXXIV Simpósio Brasileiro de Pesquisa Operacional, Rio de Janeiro, RJ. Proceedings in CD, ref. arq0223.

[106] Yanasse HH \& PINTo MJ. 2003. A new proposal for solving the minimization of the maximum number of open stacks problem. EURO/INFORMS Joint International Meeting, Istambul, Turkey. Abstract Book, p. 64. XXXV SBPO, Natal, RN, with the title: Uma nova formulação para o problema de seqüenciamento de padrões em ambientes de corte. Proceedings of the XXXV SBPO, p. 15161524, ISSN 1518-731, published in CD.

[107] Yanasse HH, Poldi KC \& Cerqueira GRL. 2011. Modified KOMBI to reduce the different patterns in cutting stock problems. IFORS 2011, Melbourne, Australia. Conference Program and Abstract Book, p. 5.

[108] Yanasse HH, Rodrigues RCM \& Senne ELF. 2009. Um algoritmo enumerativo baseado em ordenamento parcial para resolução do problema de minimização de trocas de ferramentas. Gestão \& Produção, 16(3): 370-381. ISSN 0104-530x.

[109] YANASSE HH \& SENNE ELF. 2010. The minimization of open stacks problem: a review of some properties and their use in pre-processing operations. European Journal of Operational Research, 203(3): 559-567. doi: 10.1016/j.ejor.2009.09.017. (http://dx.doi.org/10.1016/j.ejor.2009.09.017). ISSN: 0377-2217.

[110] Yanasse HH, Senne ElF \& Rodrigues RCM. 2008. An improved partial ordering scheme for solving the minimization of tool switches problem. CLAIO 2008 - XIV Congreso Latino Ibero Americano de Investigación de Operaciones, Cartagena de Índias, Colombia. Published in CD, file CLAIO_2008_173.

[111] Yanasse HH, Senne ELF \& Rodrigues RCM. 2008. Performance evaluation of some heuristics based on partial ordering for solving the minimization of tool switches problem. VI ALIO/EURO Workshop on Applied Combinatorial Optimization, Buenos Aires, Argentina. Proceedings em CD, file alioeuro2008_submission_62, ISBN 978-950-29-1116-8.

[112] YANASSE HH \& SomA NY. 1985a. Um algoritmo exato para o problema da mochila. $2^{\circ}$ Encontro Regional de Matemática Aplicada e Computacional da SBMAC, INPE, S.J. Campos, SP. (Published by INPE, ref. INPE-3645-PRE/815).

[113] YANasse HH \& SOMA NY. 1985b. A new enumeration scheme for the knapsack problem. School of Combinatorial Optimization, UFRJ, Rio de Janeiro, RJ. (Published by INPE, ref. INPE-3563PRE/769).

[114] YANASSE HH \& Soma NY. 1987a. A new enumeration scheme for the knapsack problem. Discrete Applied Mathematics, 18(2): 235-245. (Published by INPE, ref. INPE-3563-PRE/769). DI 10.1016/0166-218X(87)90024-2.

[115] YANASSE HH \& SOMA NY. 1987b. Um algoritmo pseudo-polinomial para o problema da mochila 0-1 de valor independente. XX SBPO, Simpósio Brasileiro de Pesquisa Operacional, Salvador, BA. Published in the proceedings. (Published by INPE, ref. INPE-4186-PRE/1075).

[116] YANASSE HH \& Soma NY. 1990. Finding the k-best solutions to a value independent knapsack problem. IFORS XII, Athen, Greece. (Published by INPE, ref. INPE-5390-TAE/011).

[117] YANASSE HH \& SOMA NY. 1993. A new bound for a linear diophantine equation problem. Investigación Operativa, 3(1): 69-75. 
[118] Yanasse HH, Soma NY \& Maculan N. 1994. The k-best solutions for the knapsack problem. TIMS XXXII, Anchorage, Alaska. XXVI Simpósio Brasileiro de Pesquisa Operacional (SBPO), Florianópolis, SC. Published in the proceedings, p. 308-313.

[119] Yanasse HH, Soma NY \& Maculan N. 2000. An algorithm for determining the $K$-best solutions of the one-dimensional knapsack problem. Pesquisa Operacional, 20(1): 117-134. (LAC Report, ref. LAC-008/95, pp. 01-15, São José dos Campos, SP, Brasil).

[120] Yanasse HH, ViJaykumar NL \& Olivo AA. 1996. A heuristic procedure to minimize the number of tool switches in a flexible manufacturing machine. XXVIII Simpósio Brasileiro de Pesquisa Operacional/VIII Latin-Iberian-American Congress on Operations Research and System Engineering, Rio de Janeiro, RJ. Extended abstract published, Vol. II, p. 599-603.

[121] YANASSE HH \& ZinOBER ASI. 1991. Cutting stock problems: optimal board length determination. EURO XI $-11^{\text {th }}$ European Congress on Operational Research, Aachen, Germany. (Published by INPE, ref. INPE-5383-PRE/1749).

[122] YAnasse HH, Zinober ASI \& HARRIS RG. 1991. Two dimensional cutting stock with multiple stock sizes. Journal of the Operational Research Society, 42(8): 673-683. DI 10.1057/jors.1991.133.

[123] Yanasse HH, Zinober ASI \& HARris RG. 1994. Cutting stock problems: position of free cut. Investigación Operativa, 4(1): 69-84. 